Proc. Indian Acad. Sci. (Chem. Sci.), Vol. 105, No. 6, December 1993, pp. 715-733.

(C) Printed in India.

\title{
Laser ablation of inorganic and organic materials
}

\author{
A MELE*, A GIARDINI-GUIDONI and R TEGHIL ${ }^{\dagger}$ \\ Dipartimento di Chimica, Universitá "La Sapienza" P le A Moro 5, Rome, Italy \\ ${ }^{\dagger}$ Dipartimento di Chimica, Universitá della Basilicata, Via N. Sauro 85, 85100 Potenza, Italy
}

\begin{abstract}
An intense photon flux impinging on a solid target induces the ejection of material. In a dynamic regime, the cloud may be collected on an appropriate substrate to provide the growth of solid films. Thin layer deposition of refractory semi-conductor materials, high $T_{c}$ superconductors and diamond-like (DLC) films have been obtained by pulsed laser evaporation of suitable targets. The plume which is explosively emitted from the target is formed of atoms, ions, molecules and clusters. A study of laser-induced products of various solid targets by time-of-flight mass spectrometry and luminescence analysis has shown some of the chemical pathways which follow laser evaporation and lead to nucleation and growth processes for thin film formation. Simple and complex oxides, carbon with metals, and finally graphite or organic compounds, are the materials employed as sources to grow thin film deposits. The reactivity of oxide ions formed by ablation of mixtures of simple oxides has been investigated. Metal oxide reduction during laser ablation and reaction with graphite yields carbide cluster ions prefiguring the structure of solid carbide lattices. Laser ablation of a number of organic materials has been investigated to determine the effectiveness of these targets in the formation of DLC films.
\end{abstract}

Keywords. Lasers; ablation; clusters; thin film deposition.

\section{Introduction}

Laser-induced ablation, also denoted as laser sputtering, describes the process of material removal under the action of short high intensity laser pulses. The extremely high power density that can be obtained by a sharply focused pulsed laser makes it possible to evaporate virtually every material. Ruby lasers $(694 \mathrm{~nm})$ and $\mathrm{Nd}$ : YAG lasers $(\lambda=266,355,532,1064 \mathrm{~nm})$ have all been used to vaporize a variety of material from rubber to platinum to tungsten.

There are excellent reviews on this subject (Novak et al 1983; Srinivasan and Brazen 1989), so that this report will concentrate mostly, but not exclusively, on studies carried out in the photochemistry laboratory at the University of Rome and will be related mainly with the chemical and physical aspects of this phenomenon.

\section{Laser solid interaction}

In the first age, only the thermal effect of the coherent radiation was taken into account to model the energy conversion concerning laser-material interaction with

* For correspondence 
Table 1. Thermal vs. non-thermal processes.

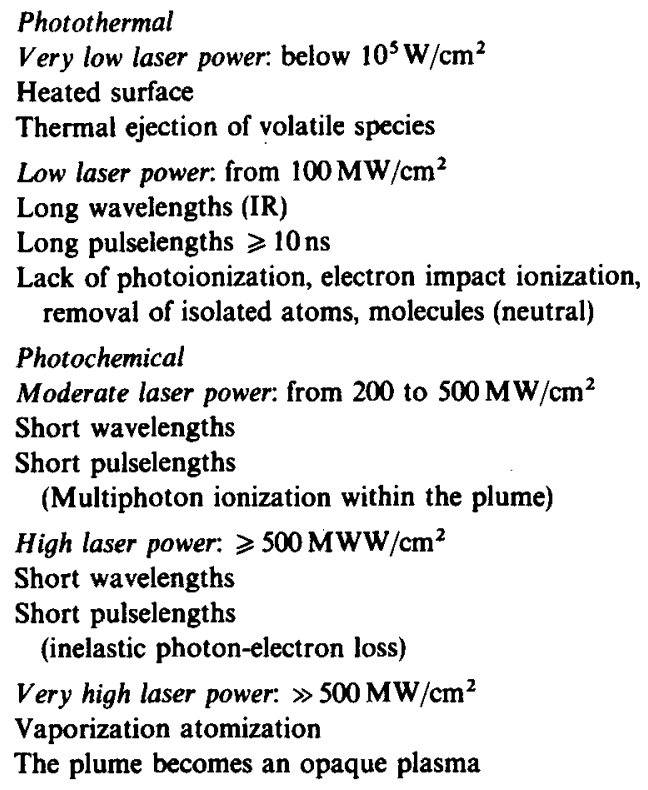

solids. With the advent of suitable $Q$-switched pulsed lasers, delivering high power laser pulses (short duration in the nanosecond range) the interaction was also described by photochemical models. Table 1 shows results for thermal and non-thermal processes on varying the laser characteristics (Srinivasan 1986; Dijkkamp et al 1987; Kuper and Stuke 1987) Photothermal laser ablation concerns the fundamental mechanism of interaction between laser rays and the solid, and the time scale for the thermalization of the excitation energy. If laser ablation is thermally activated, it can be described by the temperature and total energy change. Photochemical laser ablation is determined by the degree of selective excitation. In other words, thermal ablation refers to a mechanism in which phonons generated as a result of non-radiative transition or of electron-lattice interactions are accumulated leading to partial emission of material by vibrational motion. In electronically induced laser ablation, an accumulation of electronic excitation leads directly to bond breaking.

\section{Analysis of laser-induced vapour plume}

The luminous ejection of neutral and charged particles formed by the laser interaction with a solid surface, the so-called plume, is schematically shown in figure 1 . The plume of evaporated material is cone-shaped, characterized by a highly forward peaked distribution of the components of the target. This distribution is $\cos ^{n} \Theta$ with $1<n<12$, where the angle is measured with respect to the target normal (Kelly and Rothenberg 1985; Singh and Narayan 1990). This is in contrast to what one expects from a purely thermal expansion characterized by a $\cos \Theta$ distribution of the first order. This angular distribution indicates that material removal is a combination of different mechanisms. In addition to a change in angular distribution there is also a 

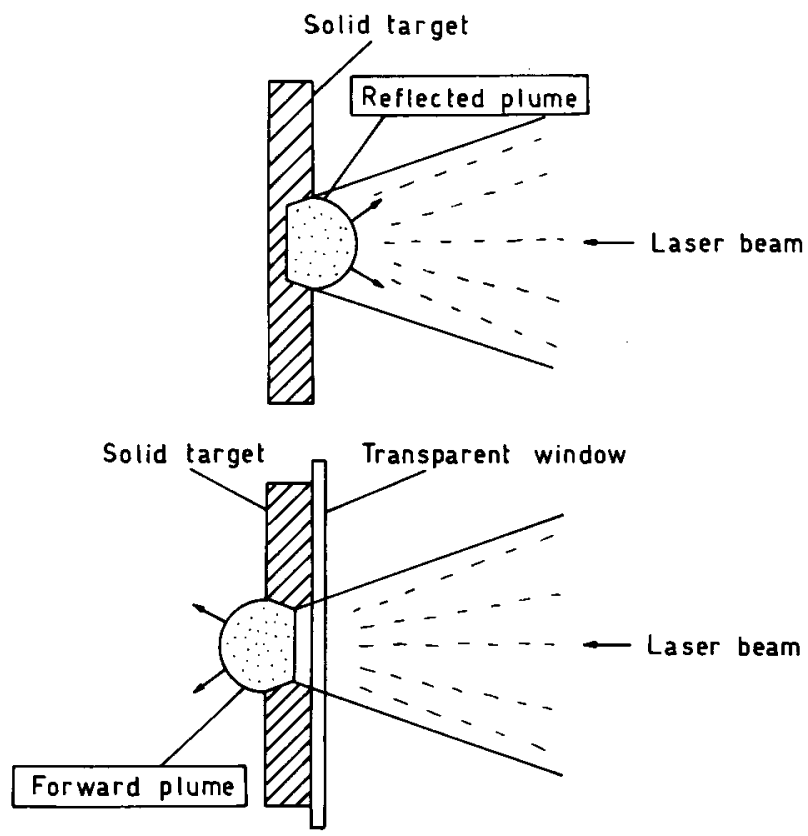

Figure 1. Schematic of the plume formed by two different configurations of laser-solic interaction.

Table 2. Angular distribution of components.

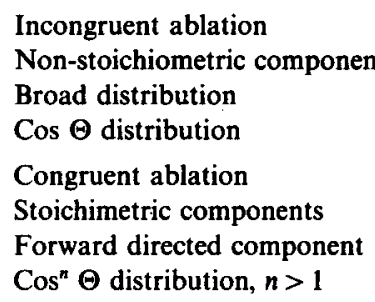

Non-stoichiometric components Low laser intensity

High laser intensity

Short pulses

variation in the composition of the evaporated material as a function of the angle of ejection. The sharp forward-peaked distribution has the same stoichiometry as the target, while the broad distribution is non-stoichiometric (table 2).

The laser energy density is critical in determining the composition of the ablated material. High laser density and short pulse lead to stoichiometric ablation. In constrast, the stoichiometry is not maintained at low laser density. A difficult process to characterize is the expansion of the plasma as it continues to interact with the laser and the ambient. This problem is especially complex for multicomponent material expanding into a reactive region.

Many spectroscopic techniques have been used to characterize the composition of the evaporated material. These techniques include emission, absorption, laser-induced fluorescence (LIF) and resonance-enhanced multiphoton ionization (REMPI). Of these, dispersed plume emission has been used most extensively to identify species in the vapour and it has provided much of the early plume characterization data. 


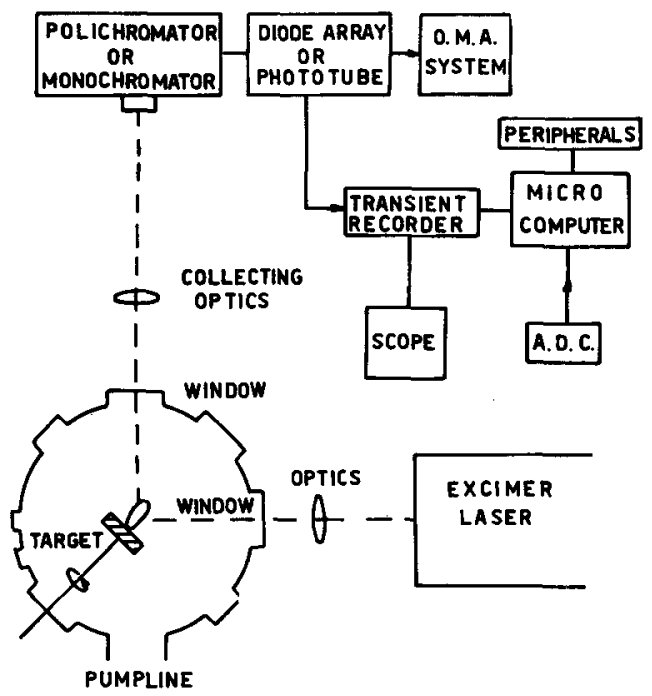

Figure 2. Optical multichannel analyser experimental arrangement for the plume analysis.

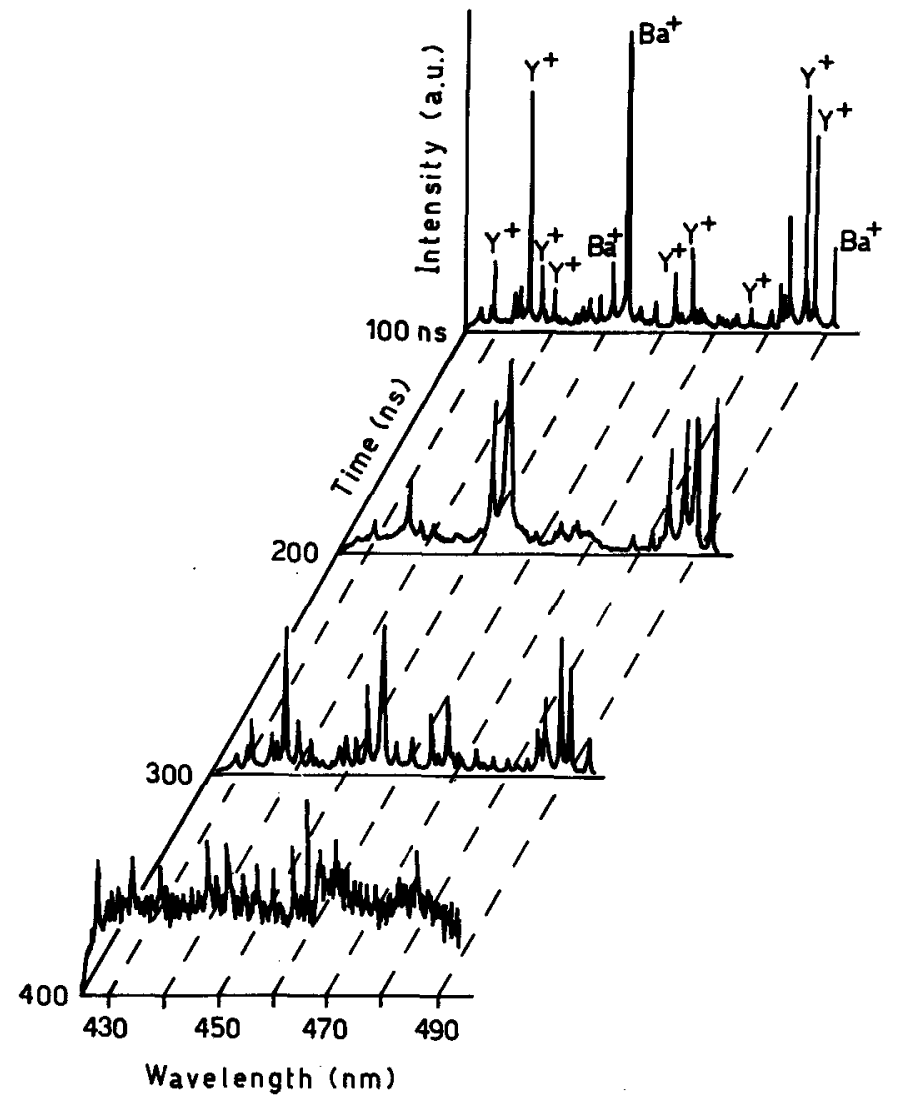

Figure 3. Time-resolved plume emission from a YBCO target. 
However, the emission monitors only the electronically excited species with measurable quantum yields for fluorescence. A schematic of an apparatus to measure luminescence from the plume is shown in figure 2 (Giardini-Guidoni and Mele 1991). Effective particle velocity has been obtained from time dependence of the optical emission intensity. Data have been collected on several emission lines for a variety of neutral and ionic species. The results indicate most probable velocities of about $5 \times 10^{5} \mathrm{~cm} / \mathrm{s}$ for neutral species and $2 \times 10^{6} \mathrm{~cm} / \mathrm{s}$ for ions. An example of dispersed plume emission from a superconductor is shown in figure 3.

Mass spectrometry is also largerly used to identify the species generated by the laser target interaction: ions and neutrals. Time-of-flight measurements yield important information on the dynamical behaviour of the laser-produced plume. In conclusion, the objective in making these measurements has been to describe both temporal and angular dependence of the desorbed species in terms of the laser and target characteristics.

\section{Cluster production and studies}

Clusters can be defined as an assembly of atoms and molecules sometimes attached to ions whose structure originates from different types of forces linking the atoms and molecules (Giardini-Guidoni and Mele 1991). Observation of gas-phase clusters has been made by several techniques. Among them, laser ablation proved to be quite successful. The variety of molecules studied is enormous. It is impossible to predict the results which are obtained, since the precise mechanism of the laser-induced plume and the subsequent processes are not completely understood.

Figure 4 shows a schematic of the laser vaporization cluster source used for cluster experiments. A pulsed laser is directed at the surface of a solid rod of the material to be studied. A high density helium flow (2-3 atm) over the target serves as a buffer gas in which clusters of the target material form, thermalize to near-room temperature, and then cool to near $0 \mathrm{~K}$ in the subsequent supersonic expansion. The content of this cluster beam can be probed by matrix isolation spectroscopy or laser-induced fluorescence, or examined by mass spectrometry of the ions formed as shown in figure 4. In other experiments, the whole material ejected from a solid target hit by the laser is analysed at each pulse by a time-of-flight mass spectrometer. This simple method of laser evaporation and ionization, shown in figure 5, leads directly to the formation of clusters with intensity and distribution which in many cases may be compared with the results obtained by the method of evaporation and subsequent supersonic expansion.

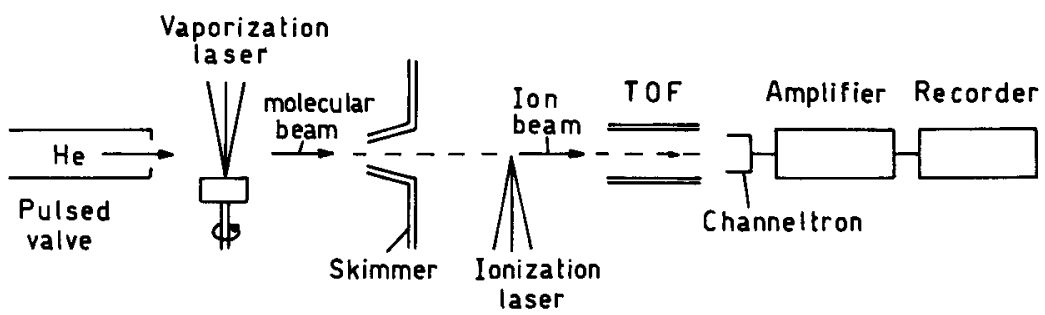

Figure 4. Laser vaporisation cluster source combined with a schematic of the TOF mass spectrometer. 


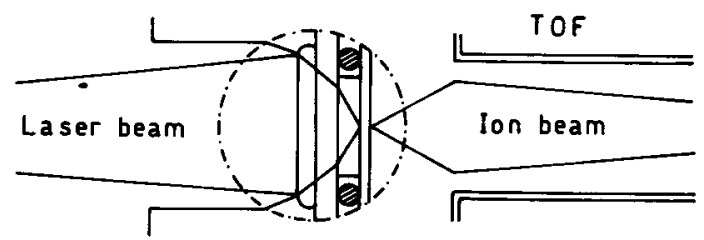

Figure 5. Sampling and grid assembling for direct laser ablation and TOF mass analysis.

Table 3. Positive ions formed by laser ablation of simple oxides

\begin{tabular}{|c|c|c|c|c|}
\hline Oxide & $\begin{array}{l}\text { Homologous series of } \\
\text { cluster ions }\end{array}$ & $\begin{array}{l}\mathrm{M}_{n} \mathrm{O}_{x} \\
n(\max )\end{array}$ & Valence & Fragment ions ${ }^{a}$ \\
\hline $\mathrm{ZrO}_{2}$ & $\begin{array}{l}{\left[\left(\mathrm{ZrO}_{2}\right)_{n}\right]^{+}} \\
{\left[\mathrm{ZrO}\left(\mathrm{ZrO}_{2}\right)_{n}\right]^{+}}\end{array}$ & 5 & 4 & $\begin{array}{l}\mathrm{Zr}^{+}(v s) ; \mathrm{ZrO}^{+}(v s \\
\mathrm{ZrO}_{2}^{+}(s)\end{array}$ \\
\hline $\mathrm{CeO}$ & $\begin{array}{l}{\left[\mathrm{Ce}(\mathrm{CeO})_{n}\right]^{+}} \\
{\left[\mathrm{CeO}\left(\mathrm{CeO}_{2}\right)_{n}\right]^{+}}\end{array}$ & 4 & 4 & $\mathrm{Ce}^{+}(s) ; \mathrm{CeO}^{+}(v s)$ \\
\hline $\mathrm{SnO}_{2}$ & $\begin{array}{l}\mathrm{Sn}_{2}^{+}: \mathrm{Sn}_{2} \mathrm{O}^{+} ;\left[(\mathrm{SnO})_{n}\right]^{+} \\
{\left[\mathrm{Sn}(\mathrm{SnO})_{n}\right]^{+}}\end{array}$ & 3 & 2 & $\mathrm{Sn}^{+}(s) ; \mathrm{SnO}^{+}(s)$ \\
\hline $\mathrm{Al}_{2} \mathrm{O}_{3}$ & $\mathrm{Al}_{2}^{+}: \mathrm{Al}_{2} \mathrm{O}^{+}$ & 2 & - & $\mathrm{Al}^{+}(v s) ; \mathrm{AlO}^{+}$ \\
\hline $\mathrm{Y}_{2} \mathrm{O}_{3}$ & $\mathrm{Y}_{2}^{2} \mathrm{O}^{+}:\left[(\mathrm{YO})_{n}\left(\mathrm{Y}_{2} \mathrm{O}_{3}\right)_{m}\right]^{+}$ & 7 & 3 & $\mathrm{Y}^{+} ; \mathrm{YO}^{+}(v s) ; \mathrm{YO}_{2}^{+}$ \\
\hline $\mathrm{La}_{2} \mathrm{O}_{3}$ & {$\left[(\mathrm{LaO})\left(\mathrm{La}_{2} \mathrm{O}_{3}\right)\right]^{+}$} & 15 & 3 & $\mathrm{La}^{+}(s) ; \mathrm{LaO}^{+}(v s)^{2}$ \\
\hline $\mathrm{MgO}$ & $\mathbf{M g}_{2}^{+} ; \mathbf{M g}_{2} \mathrm{O}^{+} ; \mathbf{M g}_{2} \mathrm{O}_{2}^{+}$ & 2 & - & $\mathrm{Mg}^{+}(v s) ; \mathbf{M g O}^{+}$ \\
\hline $\mathrm{CaO}$ & $\begin{array}{l}\mathrm{Ca}_{2} \mathrm{O}^{+}(v s) ;\left[(\mathrm{CaO})_{n}\right]^{+2} \\
{\left[\mathrm{Ca}(\mathrm{CaO})_{n}\right]^{+}}\end{array}$ & 7 & 2 & $\mathrm{Ca}^{+} ; \mathrm{CaO}^{+}(v s)$ \\
\hline $\mathrm{SrO}$ & {$\left[(\mathrm{SrO})_{n}\right]^{+} ;\left[\mathrm{Sr}(\mathrm{SrO})_{n}\right]^{+}$} & 7 & 2 & $\mathrm{Sr}^{+}(v s) ; \mathrm{SrO}^{+}(s)$ \\
\hline $\mathrm{BaO}$ & {$\left[(\mathrm{BaO})_{n}\right]^{+} ;\left[\mathrm{Ba}(\mathrm{BaO})_{n}\right]^{+}$} & 3 & 2 & $\mathrm{Ba}^{+}(s) ; \mathrm{BaO}^{+}(s)$ \\
\hline $\mathrm{SnO}$ & $\begin{array}{l}\mathrm{Sn}_{2}^{+}: \mathrm{Sn}_{2} \mathrm{O}^{+} ;\left[(\mathrm{SnO})_{n}\right]^{+} \\
{\left[\mathrm{Sn}^{+}(\mathrm{SnO})_{n}\right]^{+}}\end{array}$ & 3 & 2 & $\mathrm{Sn}^{+}(s) ; \mathrm{SnO}^{+}(s)$ \\
\hline $\mathrm{SiO}_{2}$ & $\begin{array}{l}\mathrm{Si}_{2} \mathrm{O}_{2}^{+}(s) ; \mathrm{Si}_{2} \mathrm{O}_{3}^{+}(s) \\
{\left[\left(\mathrm{SiO}_{2}\right)_{n}\right]^{+} ;\left[\mathrm{Si}^{3}(\mathrm{SiO})_{n}\right]^{+}} \\
{\left[\mathrm{SiO}\left(\mathrm{SiO}_{2}\right)_{n}\right]^{+}}\end{array}$ & 11 & 4 & $\mathrm{Si}^{+}(s) ; \mathrm{SiO}^{+}(s)$ \\
\hline $\mathrm{GeO}_{2}$ & $\begin{array}{l}\mathrm{Ge}_{2}^{+}(s) ; \mathrm{Ge}_{3}^{+}(s) \\
{\left[(\mathrm{GeO})_{n}\right]^{+}}\end{array}$ & 3 & 2 & $\mathrm{Ge}^{+}(v s) ; \mathrm{GeO}^{+}(s)$ \\
\hline $\mathbf{P b O}$ & $\mathrm{Pb}_{2} \mathrm{O}^{+}: \mathrm{Pb}_{2} \mathrm{O}_{2}^{+} ; \mathrm{Pb}_{2} \mathrm{O}_{6}^{+}$ & 2 & - & $\begin{array}{l}\mathrm{Pb}^{+} ; \mathrm{PbO}^{+} ; \mathrm{PbO}_{4}^{+} \\
\mathrm{PbO}^{+}\end{array}$ \\
\hline $\mathrm{As}_{2} \mathrm{O}_{3}$ & $\begin{array}{l}\mathrm{As}_{2}^{+}: \mathrm{As}_{3}^{+} ;\left[(\mathrm{AsO})_{n}\right]^{+} \\
{\left[\mathrm{As}(\mathrm{AsO})_{n}\right]^{+} ;(\mathrm{AsO})_{n} \mathrm{O}^{+}}\end{array}$ & 6 & 2 & $\mathrm{AsO}^{5}(v s)$ \\
\hline $\mathrm{Bi}_{2} \mathrm{O}_{3}$ & $\begin{array}{l}\mathrm{Bi}_{2}^{+}:\left[(\mathrm{BiO})_{n}\right]^{+} \\
{\left[\mathrm{Bi}(\mathrm{BiO})_{n}\right]^{+}}\end{array}$ & 4 & 2 & $\mathrm{Bi}^{+}(v s) ; \mathrm{BiO}^{+}(v s)$ \\
\hline $\mathrm{CuO}$ & {$[\mathrm{Cu}]_{m}^{+} ; \mathrm{Cu}_{2} \mathrm{O}^{+}$} & 6 & 1 & $\mathrm{Cu}^{+}(v s) ; \mathrm{CuO}^{+}$ \\
\hline
\end{tabular}

'Ions with $n=1$; (s); strong; (vs) very strong.

Ionic clusters are formed by laser ablation of simple and complex solid oxides and their mixtures. In table 3, the positive ions observed in the mass spectra of a few oxides studied among others are reported (Consalvo et al 1989; Mele et al 1989). These oxides are quite important per se and for the implications as precursors of high temperature superconducting materials as for instance $\mathrm{Y}_{2} \mathrm{O}_{3}, \mathrm{La}_{2} \mathrm{O}_{3}, \mathrm{CaO}, \mathrm{SrO}$ and $\mathrm{CuO}$. From table 3 the formation of homologous sequences of cluster ions for all oxides reported can be observed. Furthermore the mass spectrum of each oxide shows alternation, the so-called magic numbers, that is, higher ion intensities alternate with lower ones indicating preferred composition based on more stable structures. 


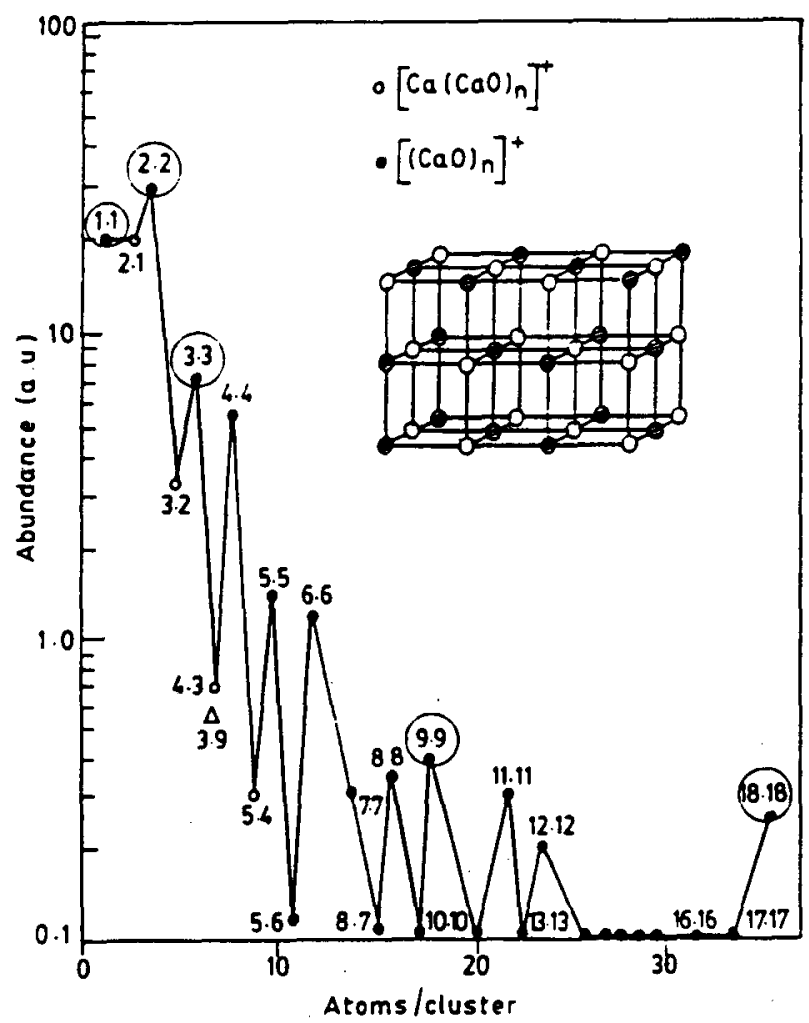

Figure 6. Positive cluster ions produced by direct laser evaporation technique of calcium oxide.

Typically the data of calcium oxide show one series (figure 6) corresponding to the stoichiometry of the solid oxide target $(\mathrm{CaO})_{n}^{+}$together with another sequence of metal rich oxide (sequence $\mathrm{Ca}(\mathrm{CaO})_{n}^{+}$). This behaviour is characteristic of other II-group oxides, $\mathrm{Mg}, \mathrm{Sr}, \mathrm{Ba}$ and of yttrium and lanthanum oxide. The intensity anomalies or magic cluster numbers are easy to understand by assuming an ionic potential (Martin 1983) between $\mathrm{Ca}^{+2}$ and $\mathrm{O}^{-2}$ ions which leads to a closed-shell structure.

The abundance maxima observed in the series are explained as arising from the exceptional stability of compact cubic structures that are essentially pieces of the face centred cubic $(f c c)$ metal oxide crystal lattice. The series corresponding to metal-rich oxide $\mathrm{Me}(\mathrm{MeO})_{n}$ can refer to an ionic model leading to abundance maxima when $n$ is one less than the maxima of the stoichiometric cluster. In fact, in the cubic structure the excess electron from the extra metal atom could be localized in an anion vacancy in the lattice analogously to a solid state $F$ center (Giardini-Guidoni and Mele 1991). The ions named 'fragment ions' in the table 3 are usually much more abundant than the cluster ions. The hypothesis is that they are produced in a very hot region of the plume by a process of fragmentation of the bulk material or of larger oxide clusters. The mass spectrum of figure 7 shows the sequences found by laser-evaporating $\mathrm{Y}_{2} \mathrm{O}_{3}$. Complexes and mixed oxides, which are precursors of superconductors, yield binary and ternary oxide clusters. The spectra shown in figure 8 refer to ablation of mixtures 


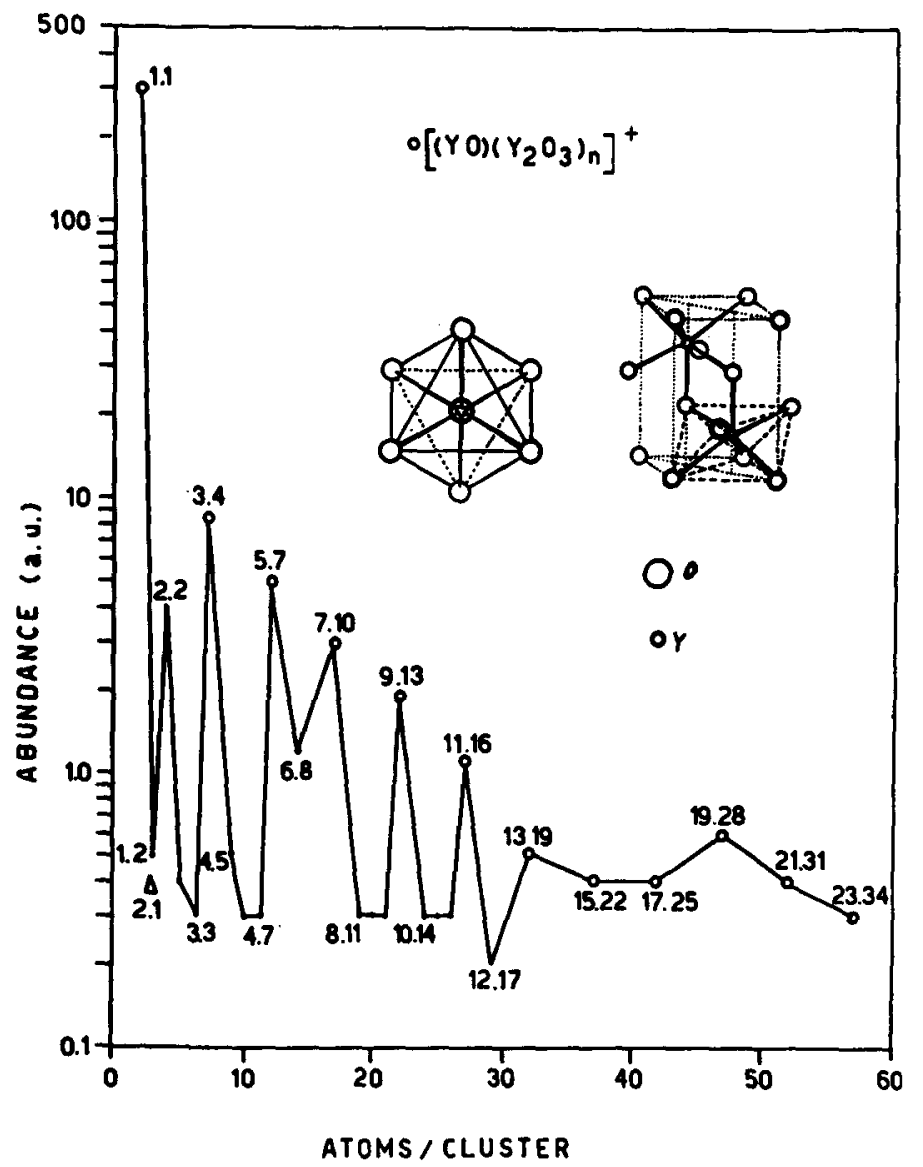

Figure 7. Positive cluser ions produced by direct laser evaporation technique of yttrium oxide.

of lanthanum, strontium and copper oxide and of a mixture of 4 components. These results simply prove that by ablation it is possible to produce copper-based complex oxides. Furthermore, it has been found that in the dynamics of the process leading to thin film deposition, the composition of the target plays an important role.

Carbon clusters have been produced by laser vaporization of a graphite rod in helium beam and probed downstream by UV laser photoionization and time-of-flight (TOF) mass analysis (figure 5) (Rohlfing et al 1984). Carbon cluster mass spectra from graphite have been also studied by direct laser evaporation and TOF detection. Both experiments, detecting positive ions, showed an even/odd intensity alternation among carbon clusters $C_{n}$ with the maximum occurring for odd $n$. The interpretation proposed for this effect was based on extended Hückel calculations which showed for linear chains, odd clusters to be more stable than even clusters (Pitzer and Clementi 1959; Hoffmann 1966).

Carbon clusters are also formed by photodecomposition of polynuclear aromatic hydrocarbons. As in graphite ablation, the peaks present in the mass spectra, shown in figure 9 for chrysene, exhibit carbon cluster $C_{n}$ with $n$ up to 600 with intensity alternations analogous to graphite. Some magic numbers, $C_{60}, C_{70}$, related to 


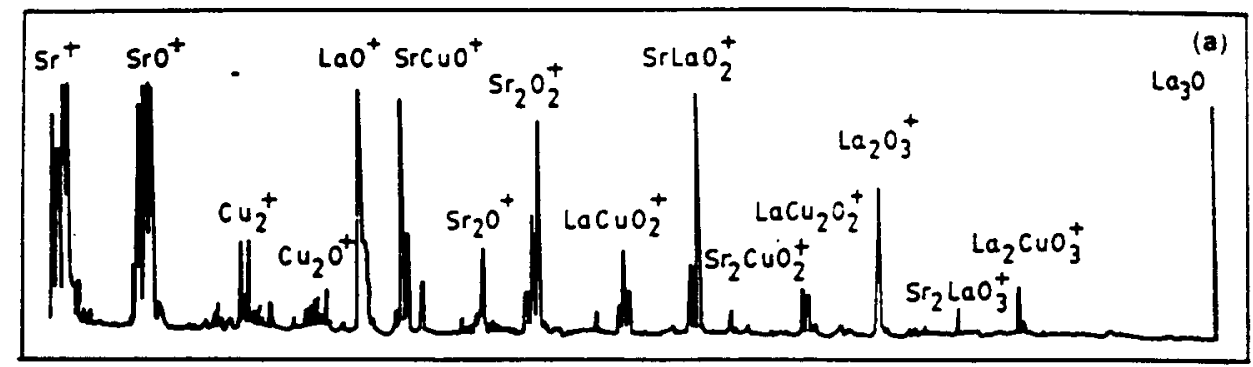

$\mathrm{La}_{1} \mathrm{Sr}_{1} \mathrm{Cu}_{1} \mathrm{O}_{3,5}$

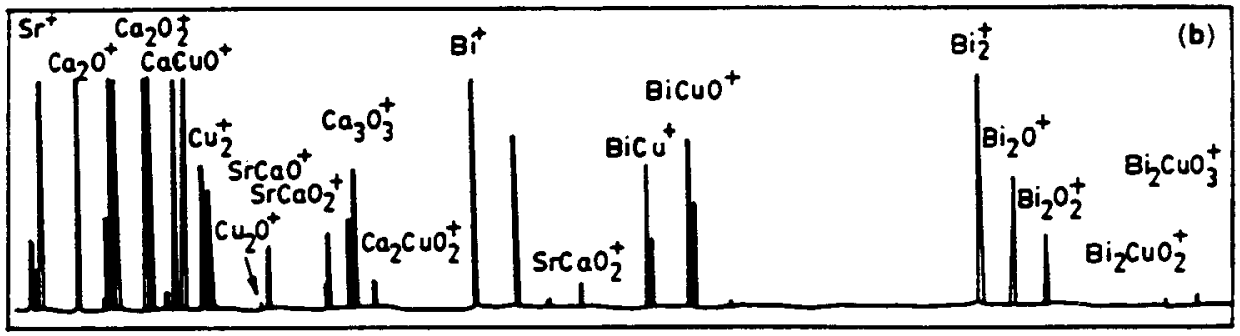

$\mathrm{Bi}_{2} \mathrm{O}_{3}-\mathrm{SrO}-\mathrm{CaO}-\mathrm{CuO}$

Figure 8. Positive cluster ions formed by direct laser evaporation: (a) mixture of $\mathrm{La}_{1}, \mathrm{Sr}_{1}$ $\mathrm{Cu}_{1}, \mathrm{O}_{3 \cdot 5}$, (b) $\mathrm{Bi}_{2} \mathrm{O}_{3}-\mathrm{SrO}-\mathrm{CaO}-\mathrm{CuO}$.

fullerene structures are also seen. It is well known that most of these aromatic hydrocarbons are noxious materials. They all have strong carcinogenic action. The use of a high power beam to decompose these materials into non-dangerous substances has been suggested. The results of laser ablation are important for the waste treatment of these substances and also for DLC thin film deposition (Giardini-Guidoni et al 1989; Lineman et al 1989).

\section{Ablation and reactivity}

The advent of the laser vaporization technique provides a useful mean to study reaction kinetics of isolated atoms and clusters. Unpublished results obtained long ago by simply laser-ablating a zirconium rod in presence of a flow of molecular oxygen are shown in figure 10 . Several zirconium oxide ions are observed in this mass spectrum, indicating that zirconium reacts with oxygen and can make clusters of various $\mathrm{Zr} / \mathrm{O}$ ratios (Giardini-Guidoni et al 1991).

Another simple laser ablation experiment concerns reactions of metal oxides with graphite. Ablation of a finely ground mixture of these two compounds produces carbide cluster ions. Formation takes place through a series of chemical reactions in the surrounding area hit by the laser beam. The scheme of these reactions is shown in figure 11 together with the mass spectra of the ions produced by reactions of lanthanum oxide and graphite (Consalvo et al 1989; Teghil et al 1990). Two extreme cases have been observed in the formation of lanthanum carbide clusters and others. In one case the mass spectra show the main sequence $\left(\mathrm{MeC}_{2}\right)_{x}^{+}$together with a carbide cluster of a more general formula $\left(\mathrm{Me}_{n} \mathrm{C}_{m}\right)_{x}^{+}$with a ratio of carbon to metal greater 

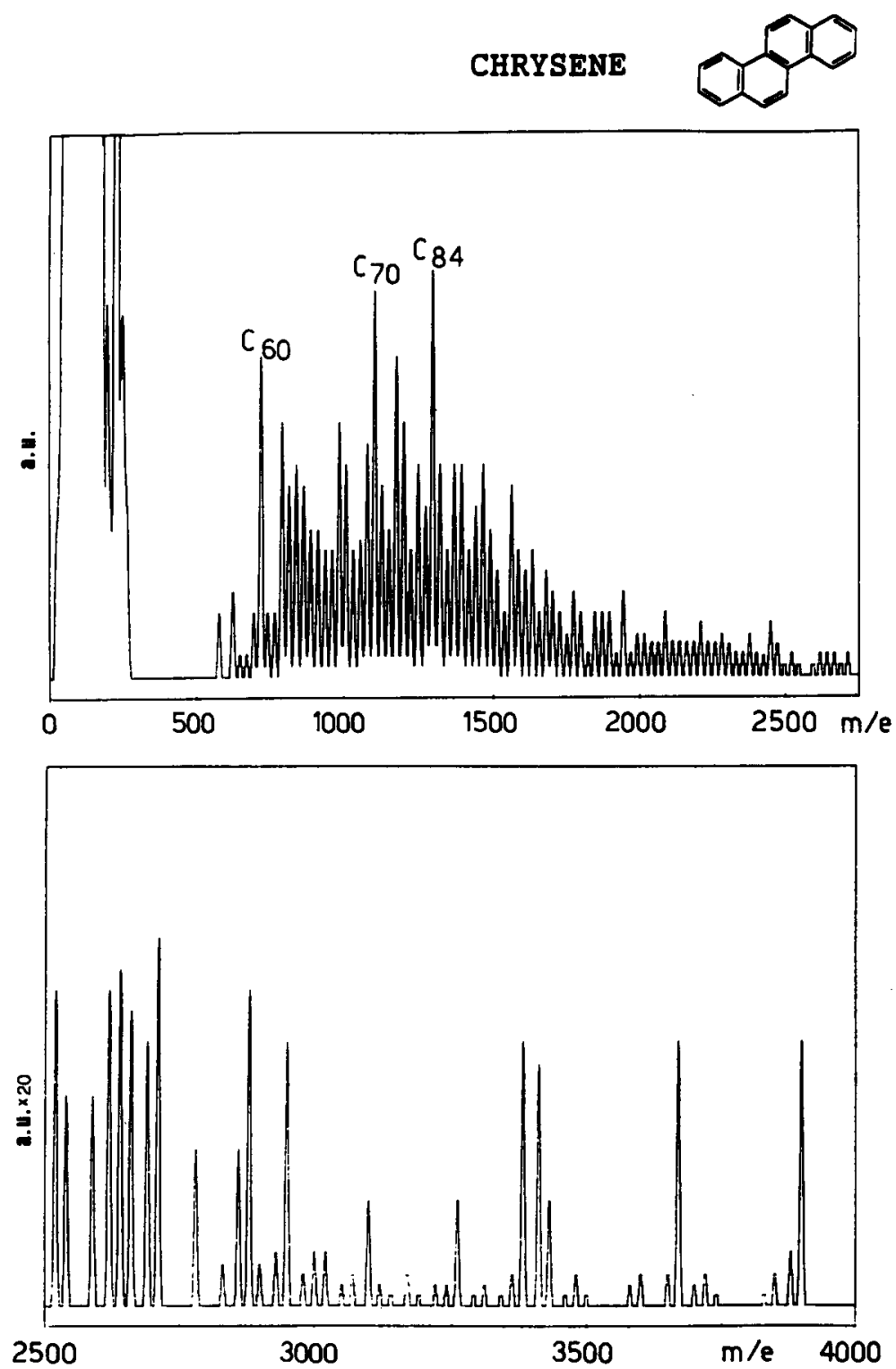

Figure 9. Positive ion TOF mass spectra obtained by direct laser evaporation of a chrysene sample (Giardini-Guidoni et al 1990).

than 2. This behaviour is probably due to the effect of the carbon atom density in the reaction region. In the other case, the spectra contains the $\left(\mathrm{MeC}_{2}\right)_{x}^{+}$sequence together with peaks corresponding to unreacted metal oxide $\mathrm{MeO}$ and metal oxicarbide $\mathrm{Me}_{x} \mathrm{O}_{y} \mathrm{C}_{z}$ cluster ions. The most typical trend is shown in the same figure 11 for a 1:1 mixture of lanthanum oxide and graphite. The even-odd alternation for these small carbide clusters may again be explained according to Clementi (Pitzer and Clementi 1959) in terms of a simple molecular-orbital theory. Neutral and positively charged odd species have a molecular orbital completely filled and are more stable than the even species with only half-filled orbitals. 


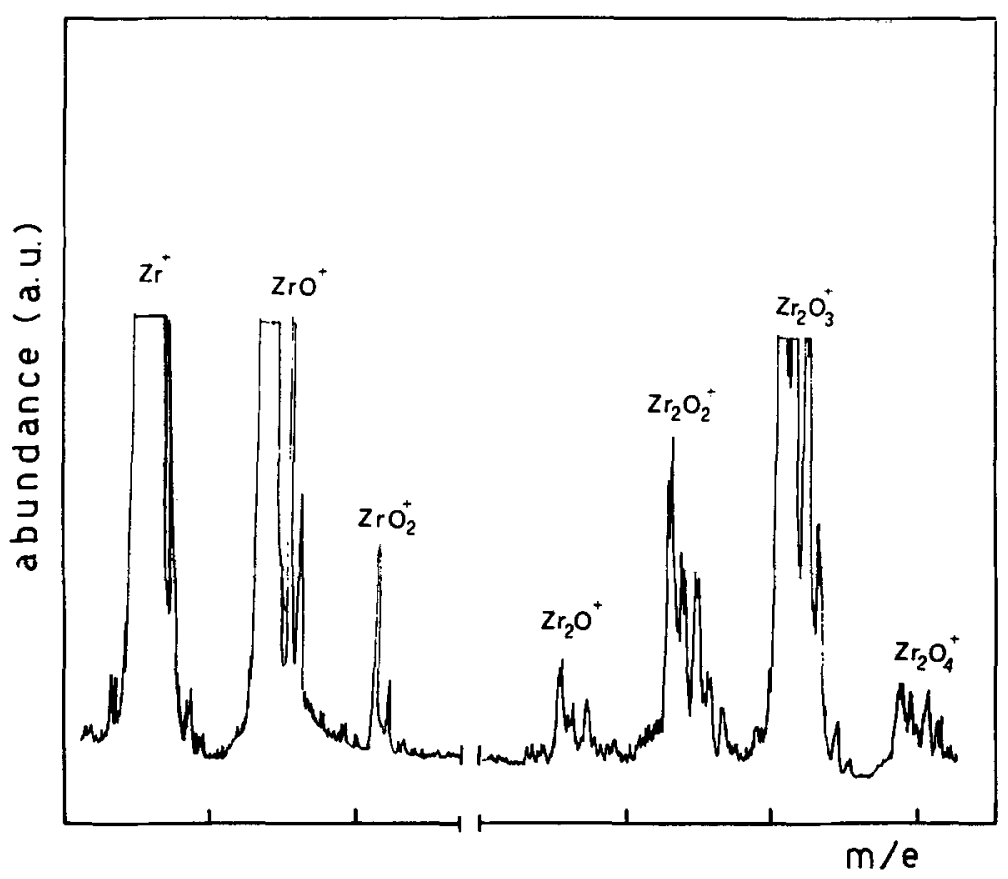

Figure 10. Positive ion TOF mass spectra formed by direct laser evaporation of a zirconium rod in an oxygen flow.

Other applications of laser ablation in this field deal with the study of reactions of metal clusters with various substances. The reactivity of clusters of metal atoms is of interest since enhanced reaction rates and new reaction pathways may result from unique cluster size, geometries and electronic structures. Additionally reactivity studies on clusters may also throw some light on the nature of cluster bonding. Metal clusters are generated by laser vaporization of a solid rod in a pulse of helium as shown in figure 4 . The clusters are then expanded into a fast flow reactor where a pulse of reactant gas mixture crosses the metal cluster beam.

Reactions of niobium clusters with benzene derivatives and a few unsaturated non-aromatic reagents have been investigated (Song et al 1990). Other studies concern reactions of vanadium clusters with propene and halopropene (St. Pierre et al 1987). New reaction pathways and chemical reactivities of metal clusters as a function of cluster size have been determined. The reaction probability was found to depend on the size of niobium clusters as well as on the structure and stability of the organic molecule. The importance of the changes in cluster geometry in determining both ionization potentials and reactivity was also studied in the reactions of iron, cobalt and nickel clusters with ammonia and water by the Riley group (Winter et al 1991). The dependence of these properties on cluster size indicates that the clusters grow with icosahedral packing. However, in many cases there is not a unique structure for a given cluster. Smalley created a sample of $\mathrm{Nb}_{19}^{+}$charged clusters and measured how quickly they reacted with hydrogen (Cheshnowsky et al 1990). He found that some of the clusters ignored the hydrogen altogether, while others grabbed the hydrogen molecule whenever they came in contact with it. This difference in reactivity was attributed to different structures. The 19 atoms in the cluster can arrange 


$$
\begin{aligned}
& \text { I case } \quad \mathrm{M}_{2} \mathrm{O}_{3}+\mathrm{C}\left[\begin{array}{ll}
\mathrm{M} \\
\longrightarrow & \left(\mathrm{MC}_{2}\right) \\
\longrightarrow & \left(\mathrm{M}_{\mathrm{n}} \mathrm{C}_{\mathrm{m}}\right)_{\mathrm{X}}
\end{array}\right. \\
& \text { II case } \quad \mathrm{M}_{2} \mathrm{O}_{3}+\mathrm{C}\left[\begin{array}{ll} 
& \left(\mathrm{MC}_{2}\right)_{\mathrm{x}} \\
\longrightarrow & \mathrm{M}_{\mathrm{x}} \mathrm{O}_{\mathrm{y}} \mathrm{C}_{2} \\
\longrightarrow & \mathrm{M}_{\mathrm{x}} \mathrm{O}_{\mathrm{y}}
\end{array}\right.
\end{aligned}
$$
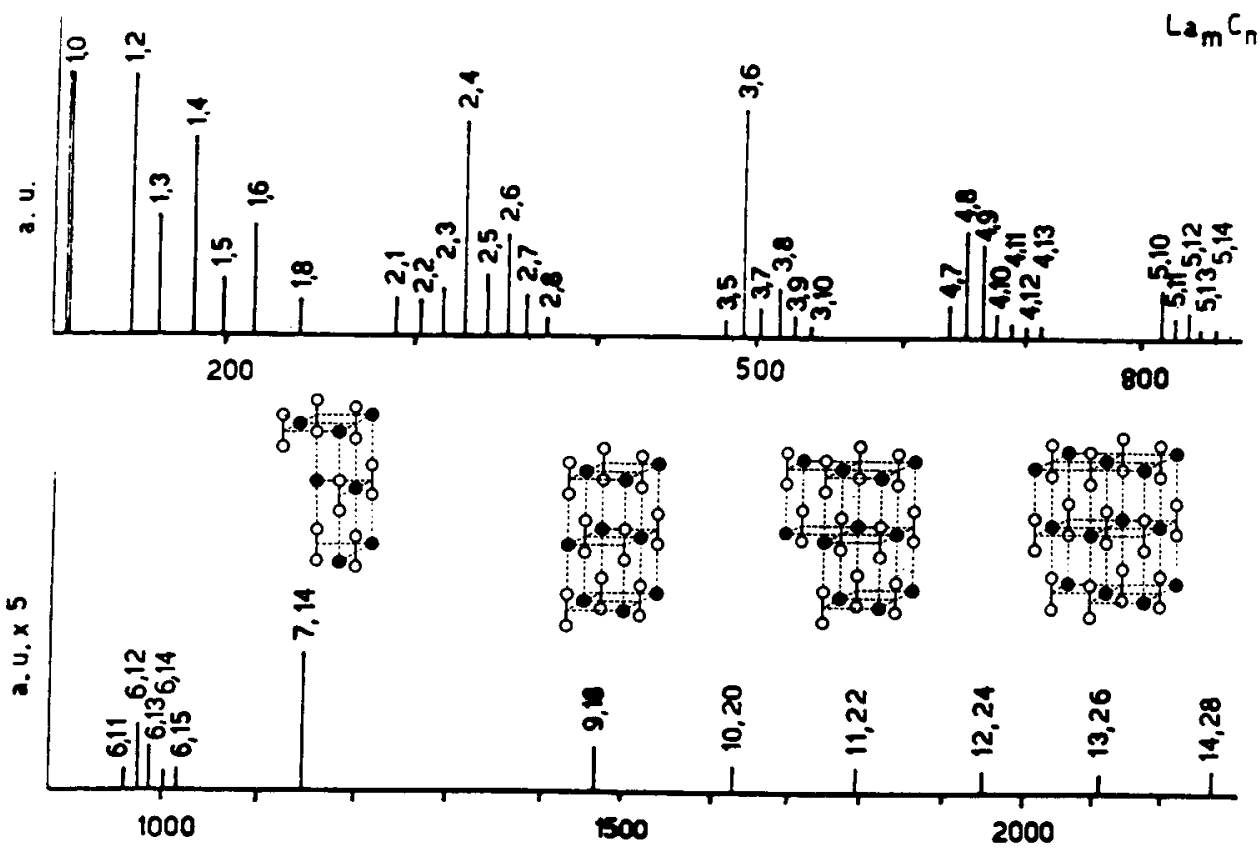

Figure 11. Schematic of the two reaction pathways determined by laser evaporation of oxides and graphite mixtures. Positive cluster ion spectra obtained by laser evaporation of a mixture of $\mathrm{La}_{2} \mathrm{O}_{3}$ and graphite.

themselves either in an eight-sided double pyramid or in a "capped icosahedron". The double pyramid has flat sides and a flat surface and reacts very poorly with hydrogen molecules. The capped icosahedron has bumpy sides and many sites for reaction with hydrogen.

Laser ablation has been applied with success to the field of organic photochemistry. The combination of laser ablation and TOF mass spectrometry has been used to determine products formed from organic compounds. The study of triazines may typically depict chemical reactions occurring during laser ablation. Triazine molecules strongly absorb in the UV regions 272 and $222 \mathrm{~nm}$ with assignments $n \rightarrow \pi^{*}$ and $\pi \rightarrow \pi^{*}$ transitions. The wavelength of a frequency quadrupled Nd-YAG laser falls in this region and therefore a photochemical process is feasible (Giardini-Guidoni et al 1989; Mele et al 1992). A schematic of the process is shown in figure 12 for a typical triazine where two different reaction pathways have been observed for all triazines examined. A retro Diels-Alder ring opening process and a cluster ion formation 

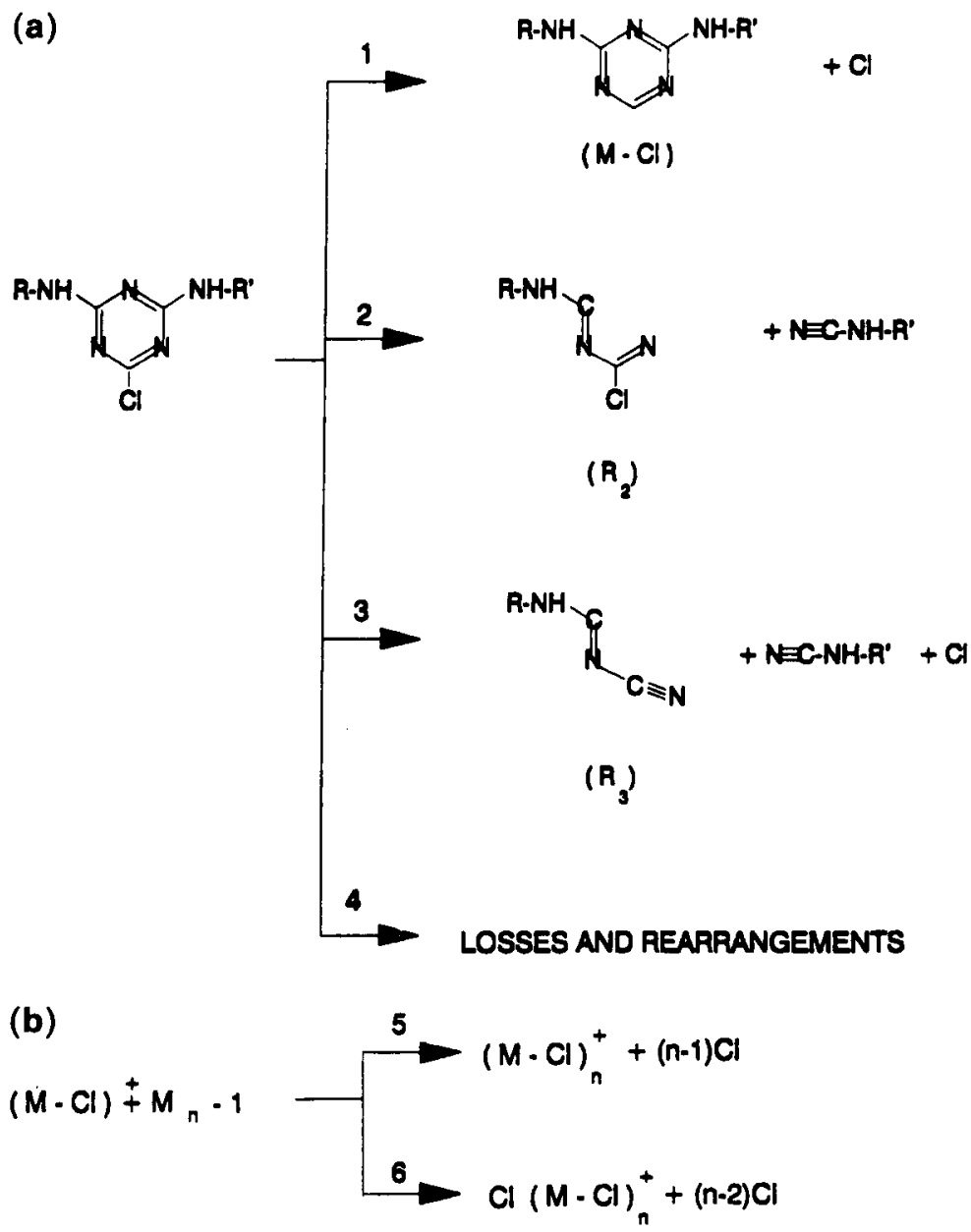

Figure 12. Schematic of the processes induced by laser ablation of triazines: (a) retro Diels-Alder ring opening; (b) cluster ion formation.

pathway (Giardini-Guidoni et al 1991) can be seen. Aggregation occurs in the dark region, fragmentation in the hot central zone of the plume.

\section{Laser ablation and deposition}

Laser ablation has received much attention in the preparation of thin film deposits. Semiconductors, metals, superconductors and dielectric films have been grown by a variety of processes involving photochemical or thermal reactions induced by pulsed-laser ablation. Although dating back to more than 20 years, this technique only recently attracted much interest particularly in the field of high temperature superconductors. The advantages of the pulsed-laser ablation approach for depositing high quality thin films for electronic device applications begin with the simplicity of the experimental setup (figure 13). All that is required is a pulsed laser, a vacuum chamber, a heated substrate holder and a target. A copper grid and a gas nozzle can 


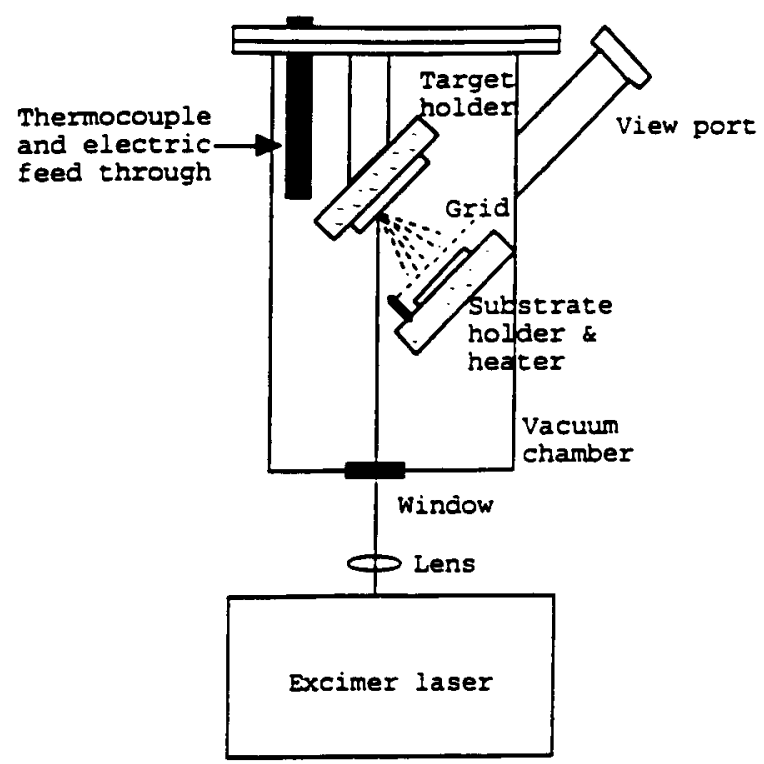

Figure 13. Schematic diagram of the apparatus used in the reflected plume experiments for thin film deposition.

also be placed. A positive or negative voltage can be applied to the grid. A buffer gas may be introduced through a gas nozzle. It has been found that for DLC deposition the voltage plays a relevant role. It is important in these experiments that the result of the evaporation yields a congruent deposition in terms of rate, composition, thickness and quality. The main objective of these studies is to understand the correlation between the target properties, the chemistry of the ablation and the resulting microstructures of the film deposited. The measurements of space- and time-dependent emission spectra of the species present in the plume provide a key to understand the dynamics and reactivity of the ablated material in the gas phase. It is fairly well established that the nucleation phenomena occur mainly at the edge of the plume and heavier aggregates are formed at a larger distance from the target. These aggregates then reach the substrate and initiate the film growth.

High $T_{c}$ thin films may be obtained from a superconducting target and laser ablation is thus the means to produce thin films. Deposition may also be obtained by direct laser ablation of a stoichiometric mixture. At present it is controversial whether a target obtained from a simple stoichiometric mixture may produce the same high quality superconducting material.

Thin film formation takes place through various stages. It starts with the neutral and ionic species being deposited on a suitable substrate and it ends with the formation of a continuous crystalline layer. It is clear that the deposition parameters play an important role in the growing process. The nucleation frequency and the coalescence process, the two most important processes, depend strongly on the deposition rate and the substrate temperature. Of course thin film preparation by laser ablation is followed by analysis of the properties of the material. In the case of superconducting materials, scanning electron microscopy examines the morphology of the film, X-ray diffraction determines the proper condition of epitaxial growth and finally electrical 
a

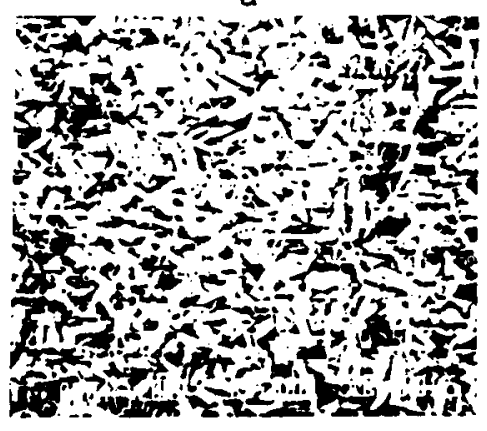

b

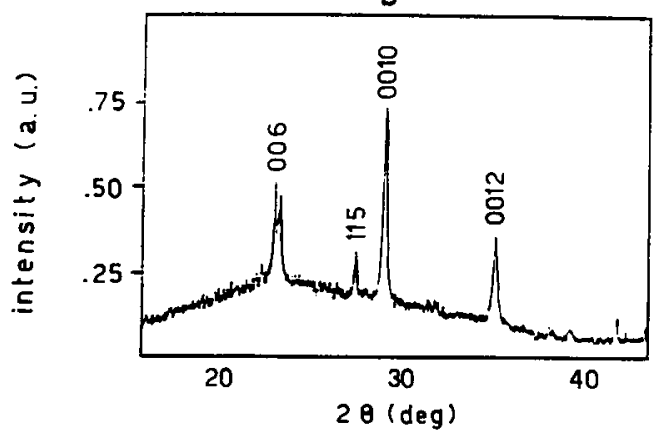

C

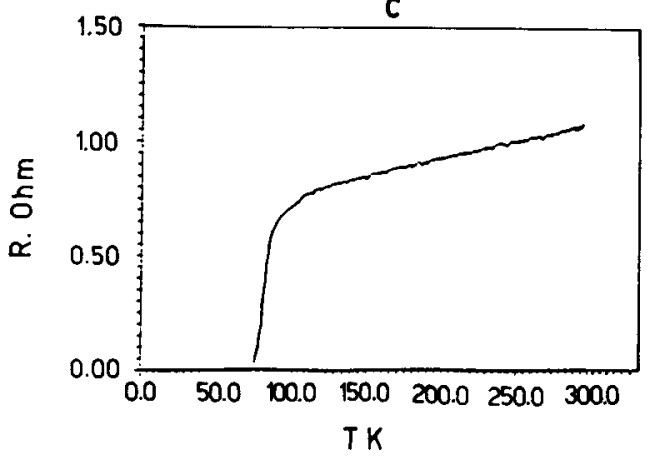

Figure 14. Techniques used for characterisation of thin film deposits: (a) SEM micrograph of a laser-ablated $\mathrm{BiSrCaCuO}$ film; (b) X-ray diffraction of a BSCCO thin film mode by laser ablation of a $\mathrm{BSCC}$ sample on $\mathrm{SrTiO}_{3}(100)$. (c) Transition resistivity curve of BSCCO thin film deposited on $\mathrm{SrTiO}_{3}$.

resistivity provides an indication of the effectiveness of the whole ablation deposition process. A few examples of these measurements are shown in figures $14 \mathrm{a}, \mathrm{b}, \mathrm{c}$.

Several interesting aspects are associated with laser-ablation deposition of the semiconductor, cadmium telluride (CdTe) (Cheung and Santur 1992). A comparison of the mass spectra of the species from the bulk by evaporative heating and by pulsed-laser ablation is shown in figure 15 . It can be seen that while $\mathrm{Cd}$ ions are present in both cases, the $\mathrm{Te}_{2}^{+}$species is present in the thermal vapour obtained from the bulk at $650^{\circ} \mathrm{C}$. This fact disturbs the homoepitaxial growth kinetics of the cadmium telluride thin film on the 111 crystallographic face. On the contrary, laser ablation provides the proper conditions for epitaxial growth. The rapid response time in pulsed-laser evaporation is another important factor and can be used for fast modulation of evaporating flux intensity. Modulation time constant is an order of magnitude greater than obtained by changing the crucible temperature in thermal evaporation, as for example in molecular beam epitaxy. There are two ways of flux modulation. One approach is to change laser power density, but a more practical approach is to change the laser repetition rate as shown in figure 16 . In one case, relative evaporation rate depends exponentially on the surface temperature and its dependence on power density is also exponential. In the second case the relationship between the evaporation rate and the repetition rate is linear (Cheung and Santur 1992). 


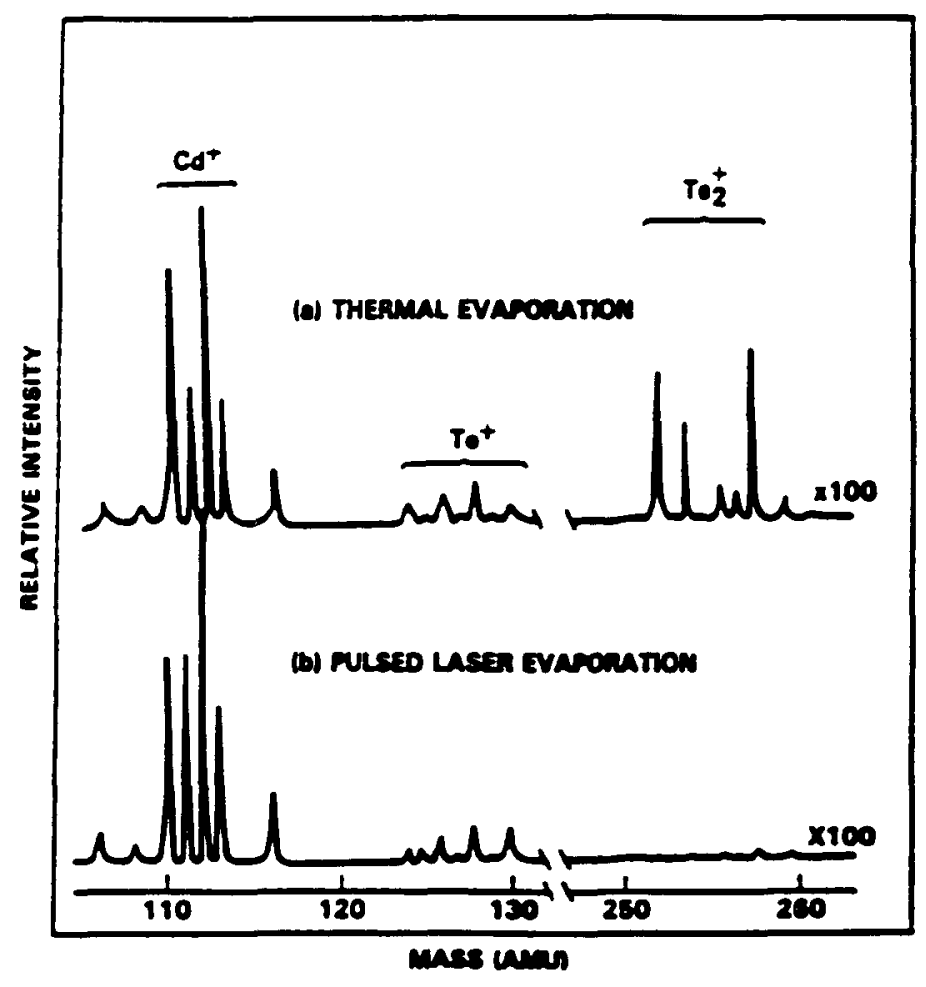

Figure 15. Mass spectra of CdTe evaporated (Cheung and Santur 1992).

Another very interesting application of laser ablation concerns the deposition of diamond-like carbon (DLC) films (Sato et al 1988). Diamond is the stablest form of carbon at high temperature and high pressure and, therefore, at first the idea was to convert graphite directly into diamond. More recently the synthesis of metastable diamond at low pressure was also explored. A high activation energy between stable and metastable states may provide a barrier to interconversion. DLC refers to this product which is synthesized not in the diamond stable region but under metastable conditions, that is, in the graphite region. Various products have been utilized as targets to deposit DLC thin films. These substances are shown in table 4. The deposited film exhibited properties characteristic of DLC material, as confirmed by high electrical resistivity, optical transparency in the infrared, chemical inertness and mechanical hardness with high refractive index (Athwal et al 1992). In figure 17 plots of the DLC film thickness of the various substances studied as a function of the number of laser pulses is shown. From the slope of each line, deposition rates between 3.4 to $27.4 \AA$ /pulse have been calculated. Deposition from graphite is much slower. The data on the hybridization and structure of the various compounds used as target for DLC deposition are shown in table 5. The diamond structure is also reported. It can been seen that in moving from planar or purely aromatic structures to fullerene or fullerene shells, the main change is due to a different carbon atom configuration which exhibits varying degrees of strain or a tendential C $s p^{2} \rightarrow \mathrm{C} s p^{3}$ hybridization. The mechanism by which carbon atoms can rearrange themselves is not straightforward. There is an ordering process that takes place during ablation and condensation of 


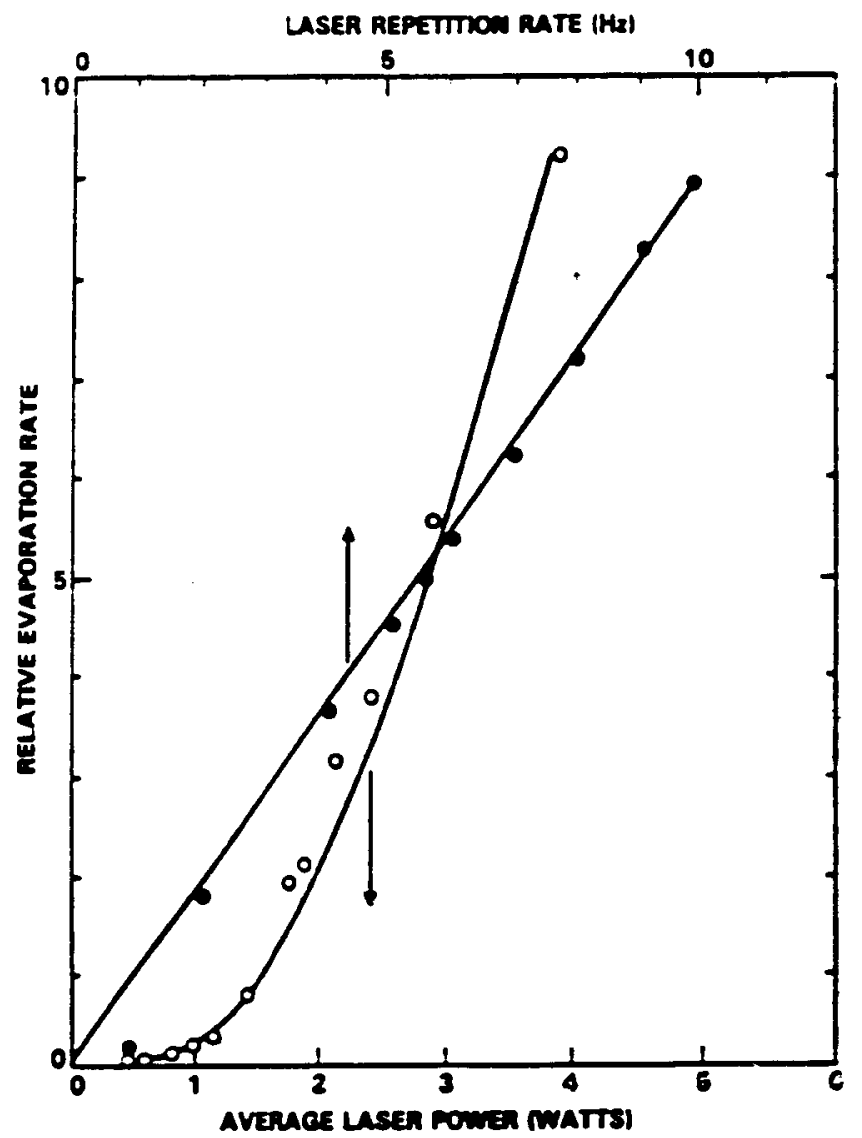

Figure 16. Evaporation rate modulation by changing the laser power density and changing the repetition rate (Cheung and Santur 1992).

Table 4. Targets used for DLC thin film deposition.

Graphite

PMMA (polymethylmethacrylate, $\mathrm{C}_{5} \mathrm{H}_{10} \mathrm{O}_{2}$ )

Chrysene $\left(\mathrm{C}_{18} \mathrm{H}_{12}\right)$

Violanthrone $\left(\mathrm{C}_{34}^{12} \mathrm{H}_{16} \mathrm{O}_{2}\right)$

Fullerene $\left(\mathrm{C}_{60}\right)$

carbon vapour. Diamond stability is about only $10 \mathrm{meV}$ lower than that of graphite. Laser ablation produces necessarily both $\mathrm{C} s p^{2}$ and $\mathrm{C} s p^{3}$ configuration in different ratios. The shock wave formed in the expansion of the vapour and the high temperature may both favour a $\mathrm{C} s p^{3}$ configuration in the deposition process.

\section{Conclusions}

In this review, the process of laser ablation has been very briefly described. A simple outline of the perceived mechanism in terms of energy deposition on the target, 

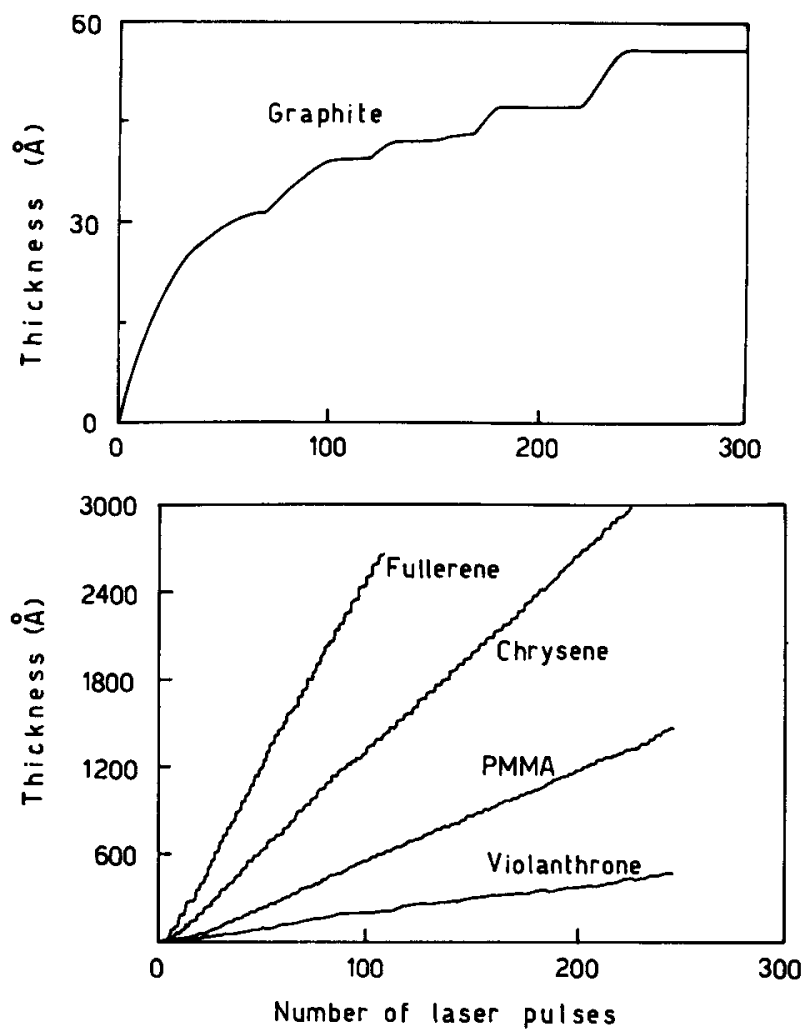

Figure 17. DLC film thickness versus number of laser pulses for various solid targets.

Table 5. Schematic of structures and hybridization of substances used as targets for DCL thin film deposition.

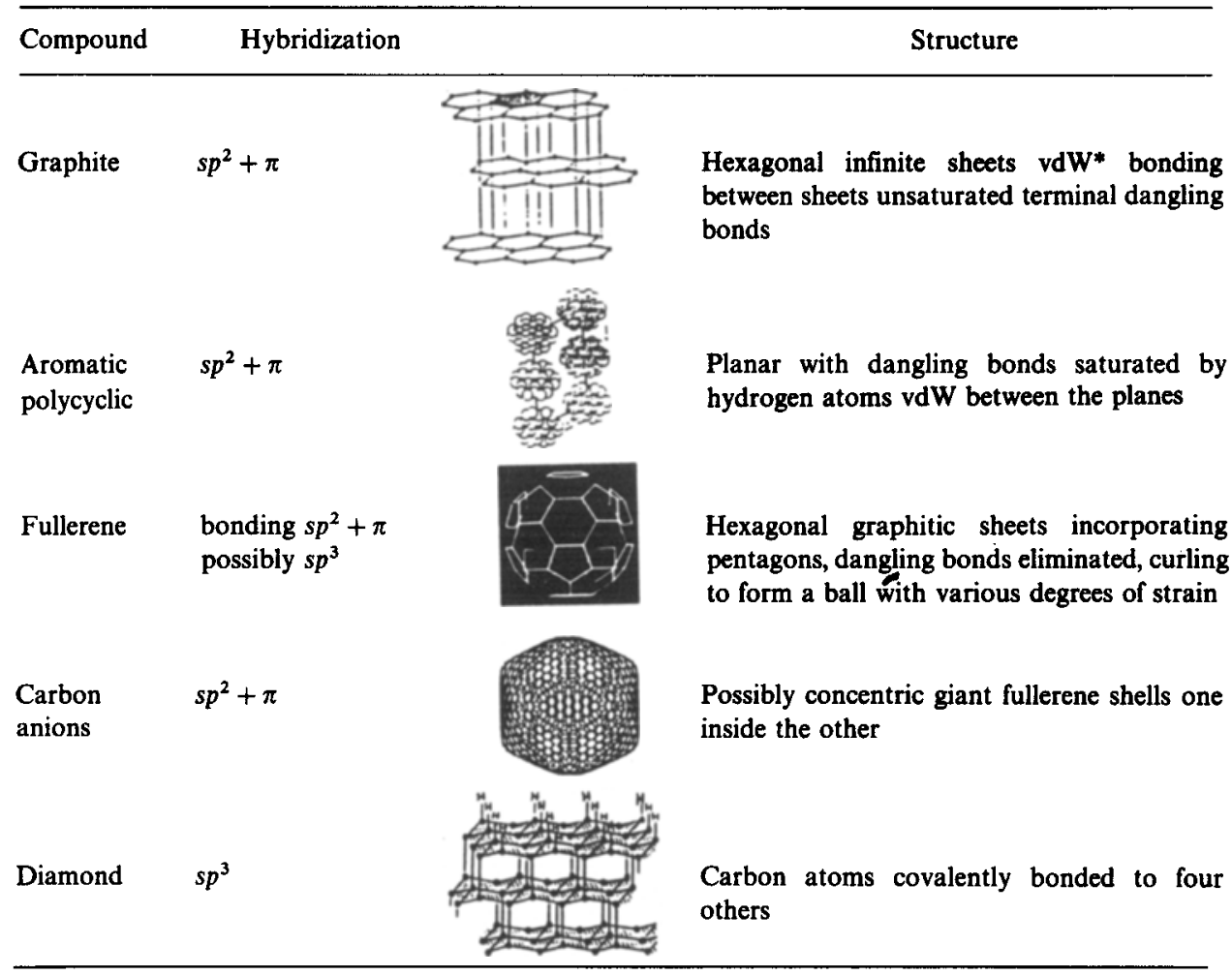


particle ejection and plume dynamics has been presented here. Laser ablation has tremendous exciting potential and offers many advantages over traditional methods in a variety of fields, ranging from spectroscopy and reactivity to thin film deposition, as seen from the few examples shown.

\section{Acknowledgement}

This work was partly supported by CNR project "chimica fine".

\section{References}

Athwal I S. Mele A and Ogryzlo E A 1992 Diamond and related material 1731

Cheshnovsky O, Taylor K J, Conceicao J and Smalley R E 1990 Phys. Rev. Lett. 641785

Cheung J T and Santur H 1992 Laser Ablation of electronic materials (eds) E Fogarassy and S Lazon (Amsterdam: North Holland) p. 325

Consalvo D, Mele A, Stranges D, Giardini-Guidoni A and Teghil R 1989 Int. J. Mass Spectrom. Ion Process. 91319

Dijkkamp D, Gorda A S and Venkatesan T 1987 Phys. Rev. Lett. 582142

Giardini-Guidoni A and Mele A 1991 Laser Chem. 11205

Giardini-Guidoni A, Mele A, Pizzella G, Fantoni R, Lazic V, Moliterni A G G and Snels M 1991 Proceed. Int. Conf. on "Laser 91", p. 821

Giardini-Guidoni A, Moroni A, Snels M, De Simone E, Salvi A M, Fantoni R, Berden W C M and Giorgi M 1990 Appl. Surf. Sci. 46321

Giardini-Guidoni A, Teghil R, Morone A, Snels M, Mele A, Letardi T and Di Lazzaro P 1989 Proc. Int. Conf. on Lasers 89731

Hoffmann R 1966 Tetrahedron 22539

Kelly R and Rothenberg E 1985 Phys. Res. B7/8 755 and reference therein

Kuper S and Stuke M 1987 Appl. Phys. B44 199

Lineman D N, Viswanadham S K, Sharkey A C and Hercules A M 1989 Microbeam analysis(ed.) P E Russel (San Francisco: San Francisco Press) p. 297

Martin T P 1983 Phys. Rep. 95167

Mele A, Consalvo D, Stranges D, Giardini-Guidoni A and Teghil R 1989 Appl. Surf. Sci. 43398

Mele A, Giardini-Guidoni A, Teghil R, Pizzella G and Letardi T 1992 Mol. Cryst. Liq. Cryst. 219193

Novak F P, Balasanmugam K, Viswanadham K, Parker C D, Wilk Z A, Mattern D and Hercules D M 1983 Int. J. Mass Spectrom. Ion Phys. 53135

Pitzer K S and Clementi E 1959 J. Am. Chem. Soc. 814477

Rohlfing E A, Cox D M and Kaldor A 1984 J. Chem. Phys. 813322

Sato T, Furano S, Iguchi S and Hanabusa M 1988 Appl. Phys. A45 355

Singh R K and Narayan J 1990 Phys. Rev. $\mathbf{B 4 1} 8843$

Song L, Freitas J E and El-Sayed M A 1990 J. Phys. Chem. 941604

St. Pierre R J, Chronister E L and El-Sayed M A 1987 J. Phys. Chem. 915228

Srinivasan R 1986 Science 234559

Srinivasan R and Brazen B 1989 Chem. Rev. 891303

Teghil R, Giardini-Guidoni A, Piccirillo S, Mele A and Polla-Mattiot F 1990 Appl. Surf. Sci. 46220

Winter B J, Klots T D, Parks E K and Riley S J 1991 Z. Phys. D19 375 